\title{
Reusing Phosphorus: Engineering Possibilities and Economic Realities
}

Elisabeth Kvarnström

and

Mats Nilsson

Recycling is becoming increasingly important in rich societies both in a physical sense and in the perceptions about desirable changes of economic activity and behavior. In both respects, the significance of recycling is greatest for the raw materials of agricultural, forest, and mineral origins. Recycling of phosphorus, i.e., secondary phosphorus originating from wastewater, is discussed in this paper.

The recycling of phosphorus from wastewater currently involves the reuse of sewage sludge in agriculture. In Sweden, 84 percent of the population is connected to wastewater treatment plants where phosphorus is removed from the wastewater [SCB 1995a], hence producing sludge containing high levels of phosphorus. The phosphorus content is 6,000 metric tons per year in Swedish wastewater treatment plant sludge. This represents approximately 30 percent of the commercial phosphorus fertilizer used yearly in Sweden [NV 1996].

The use of sewage sludge in agriculture has been discussed widely in Sweden during the 1990s. Far from resolving several important issues, such as the content of pollutants in the sludge and whether the content of phosphorus in sludge can be used by plants, the debate is still raging. The recoverability and value of phosphorus in sewage sludge depend on its quantity, location, and the sludge quality. ${ }^{1}$ Sewage

The authors are Licentiate of Technology of Division of Sanitary Engineering, Lulea University of Technology, and Licentiate of Philosophy of Division of Economics, Luled University of Technology, Sweden. The authors greatly appreciate the valuable input offered by the respondents to the questionnaire. The authors acknowledge financial support from the Swedish Board for Water and Wastewater Research, the Swedish Council for Building Research, and the Kempe Foundation. This paper was presented at the annual meeting of the Association for Evolutionary Economics, New York City, New York, January 3-5, 1999. 
sludge is often favorably affected by the first criterion but unfavorably affected by the last two criteria.

\section{Objectives and Method}

This paper is interdisciplinary, and the objective is to investigate the factors determining the use of secondary phosphorus as viewed by the suppliers. Future secondary phosphorus alternatives, as viewed by the secondary phosphorus suppliers, are discussed. The method employed was to send a questionnaire (see Table 1) to 73 out of 288 municipalities in Sweden. The addressee was generally a sanitation engineer, who represents the supply side of the secondary phosphorus "market."

\section{Background: Sewage Sludge Use in Sweden}

The macro-nutrients necessary for plant growth are nitrogen, phosphorus, and potassium. There is a constant flow of phosphorus from agriculture toward urban

\section{Table 1. Topics in the Questionnaire Discussed within This Paper ${ }^{\mathrm{a}}$}

\section{Topics}

Current secondary phosphorus use:

Current sludge utilization

The role of the sludge council

Has sludge quality been discussed and, if so, which aspects

Price of sludge, and estimated relative prices of substitutes

The relevance of the food industry's arguments in the sludge debate

Rank existing alternative technologies

Institutional factors and their relevance for secondary phosphorus use

Future secondary phosphorus use:

Important determinants for increasing sludge use

The effect of a lower relative price of sludge

Suggestions for policy changes to increase secondary phosphorus use

Rank alternatives to conventional wastewater treatment

\footnotetext{
${ }^{a}$ To acquire the necessary data, a questionnaire was sent to 73 municipalities in 5 of Sweden's 24 counties. This covers about one-fourth of all municipalities in Sweden. The share of respondents who answered was 51 percent. The five counties were randomly chosen. The group of respondents is sanitation engineers in charge of wastewater treatment and use of sewage sludge.
} 
areas due to "exportation" of food. Around 60 percent of this phosphorus can be found in toilet waste [Kirchmann 1998].

In Sweden, about 30 percent of the sludge produced is reused in agriculture. However, the Recycling Act, passed by the Swedish government in 1994, states that a certain sludge quality must be reached to allow for the utilization of sludge within agriculture. ${ }^{2}$ An agreement on quality assurance for sludge utilization was reached in 1994 among the Swedish Environmental Protection Agency, the Federation of Swedish Farmers $\left(\mathrm{LRF}^{3}\right)$, and the Swedish Water and Wastewater Association. Part of the agreement involved the establishment of national, regional, and local sludge utilization agreement councils, whose members include farmers and representatives from municipalities and consumer organizations. The establishment of these sludge councils has increased sludge utilization from 20 percent before the establishment of the councils to 30 percent in 1996 [NV 1996].

It is noteworthy that the allowed yearly deposition of cadmium ${ }^{4}$ on arable land in Sweden is $1.75 \mathrm{~g}$ of $\mathrm{Cd} / \mathrm{ha}$. The same figure for the United States in 1994 was $1,900 \mathrm{~g} / \mathrm{ha}$ [Larsson 1995]. This indicates the stringent approach to sludge utilization in Sweden. Many municipalities conform to the strict regulations concerning sludge quality ${ }^{5}$ but still do not find any use for their sludge [NV 1996].

In attempting to market their sludge, Swedish municipalities must also overcome the food industry's dislike of sludge utilization on crops. It is concerned with the transmission of heavy metals and organic compounds from sludge to humans via soil and animals. Several environmental organizations in Sweden are against the utilization of sewage sludge in agriculture. The EU regulations for organic food production do not allow sludge to be used for crop production [personal communication, Rut Björling, Swedish Association for Organic Food Production].

These difficulties have raised the demand for alternatives to conventional treatment plants in order to obtain more "pure" secondary phosphorus. One approach is to produce a phosphorus fertilizer from conventional wastewater sludge [NV 1997], or the removal of heavy metals from sewage sludge by acid leaching [NV 1997; Levlin et al. 1996]. Phosphate crystallization and ion exchange are other techniques available [Brett et al. 1997].

A less conventional wastewater treatment option that can be suitable in smallerscale systems is the installation of toilets that separate urine, which contains about 67 percent of the phosphorus excreted from the body, from the more unclean feces [Kirchmann 1998]. Urine can then be used as a fertilizer after six months of storage [Höglund et al. 1998]. Ȧsa Hanaeus and Erica Johansson [1996] found 11 larger installations of urine source separating systems in Sweden. Liquid composting of toilet waste and solid waste is a method employed in Norway [Jenssen and Etnier 1997]. ${ }^{6}$ 


\section{Results and Discussion}

The most important results are displayed in Table 2 .

Table 2. Selected Results from the Survey

\begin{tabular}{ccccc}
\hline \hline & & \multicolumn{2}{c}{ Current Sludge Use } & \\
Agriculture & Forestry & Construction & Landfill & Other \\
\hline $70 \%$ & $0 \%$ & $11 \%$ & $12 \%$ & $7 \%$
\end{tabular}

Ranking of the Five Most Important Sludge Quality Aspects

1. Accumulation of heavy metals in soil

2. Accumulation of persistent organic compounds in soil

3. Disease transmission on spreading occasion

4. Transmission of heavy metals from soil to plants

5. Disease transmission plant-animal

\begin{tabular}{ccc} 
& \multicolumn{2}{l}{ Sludge Price } \\
Negative & 0 & Positive \\
\hline $12 \%$ & $64 \%$ & $24 \%$
\end{tabular}

Ranking of the Four Most Important Institutional

Factors Preventing Secondary Phosphorus Use

1. Traditions within farming

2. Attitude of food industry

3. Existing water and wastewater infrastructure

4. The environmental movement

\section{Ranking of the Three Most Important Determinants for Increasing Sludge Use}

1. Acceptance of sludge by food industry

2. More knowledge about impact of sludge use on soil-plant-human beings

3. Improved sludge quality

\section{Most Important Law or Regulation to Change to Increase Secondary Phosphorus Use (Open Question)}

Heavier taxes on commercial fertilizers

Ranking of Future Altematives for Secondary Phosphorus in Agriculture

\section{Wastewater irrigation}

2. Production of fertilizers from sewage sludge

3. Urine source separation 


\section{Current Sewage Sludge Use}

The average amount of sludge used in agriculture by the municipalities answering the questionnaire is 70 percent, which is higher than the 30 percent average for Sweden cited elsewhere in the literature [NV 1996]. The respondents are divided into two groups, with utilization rates of either 100 percent or 0 percent. Taking into account mean sludge utilization within the responding counties, the expected sludge utilization would be 53 percent [SCB 1995b]. The additional 18 percent included in our survey may be due to an increase in sludge utilization after 1995, or due to a bias in the material. The average municipality in this survey conforms to the goal set by the Swedish EPA that at least 60 percent of the sewage sludge be used in agriculture [NV 1996].

All but one respondent answered that sludge quality had been discussed within the municipality. The sludge quality question of most concern among the respondents was the accumulation of heavy metals in the soil. It is highly important that the productivity of the arable land is not endangered due to the use of waste in agriculture [Kirchmann 1988]. Sludge utilization in agriculture will, for most metals, cause an accumulation of metals in the soil. For cadmium, this accumulation is not acceptable in the long run [Pettersson 1992]. The second most important question was the concentration of persistent organic compounds. Persistent organic compounds are a great concern for milk production [Johansson 1997]. The availability of phosphorus for plants had not been discussed in many municipalities. To us, this was surprising since the major reason for applying sludge to arable land is to provide plants with phosphorus.

\section{Secondary Phosphorus Price}

The prices of phosphorus given in the questionnaire varied between a high of 11 $\mathrm{SEK} / \mathrm{kg}$ and a low of $-20 \mathrm{SEK} / \mathrm{kg}$ (the average exchange rate in 1998 was 8.05 SEK/\$US). This should be compared with the price of commercial fertilizer, which is approximately $10 \mathrm{SEK} / \mathrm{kg} \mathrm{P}$ [personal communication, Göte Bertilsson, HydroAgri]. Assuming that sewage sludge meeting the requirements of the Swedish EPA is of good quality, our results show that the price of sewage sludge is determined by demand. Hence only municipalities with a demand equal to their full capacity will be able to charge a price. In some cases, the municipalities subsidize the use of sewage sludge, and often the sewage sludge is delivered free of charge. The price floor for the individual sewage plants is the cost to deposit the sludge. ${ }^{\top}$ A disposal charge of $250 \mathrm{SEK} / \mathrm{metric}$ ton is discussed. In a wider perspective, the gains (or losses) of not depositing the sludge may change this price floor in any direction. ${ }^{8}$

Not surprisingly, subsidies help to promote the use of sewage sludge. In cases where subsidies were used, the demand reached the capacity level. The rather poor 
connection between the output of secondary phosphorus into the market and the price of sewage sludge suggests market imperfections created by institutional problems, or a product of poor quality not in demand.

\section{Ranking of the Four Most Important Institutional Factors Preventing Secondary Phosphorus Use}

The most important factor (from the perspective of the "sellers" evaluating the "buyers") is the traditions within farming, i.e., farmers are used to commercial fertilizers and manure. Assuming that farms are profit seeking enterprises, this is hard to understand. Our conception of farmers is that they are conservative, but we would like to suggest a few possible alternative explanations of why they may be slow in adopting this substitute to the foremost commercial fertilizers. First, there are still unsolved issues concerning the use of sewage sludge. We believe that, in cases of uncertainty regarding what will happen to the soil, farmers are a risk-averse group. Second, the Federation of Swedish Farmers is basically in a monopoly position when distributing fertilizers. Although it may be in the interest of individual farmers to have more substitutes introduced in the market, why should the Federation wish to relinquish its market power? ${ }^{9}$ Unfortunately, our investigation lacks the data to confirm or reject any of the suggested alternatives.

The second most important factor was the food industry. The food industry's main argument is that consumers would avoid food grown using sewage sludge. Our survey shows no clear connection between this argument and sludge utilization in these municipalities. A priori, we would have expected municipalities where this argument was put forward to have a low output. Our explanation of this puzzle is that there are enough farmers producing crops that do not involve the food industry, e.g., energy crops or seeds for sowing.

One important obstacle to increasing the use of secondary phosphorus is the existing water and wastewater infrastructure. The existing infrastructure ranked as the third most important hindrance to phosphorus recycling among the respondents. The main goal of this sanitary system was to guarantee the hygienic conveyance of wastewater from dwellings to treatment plants. However, the current system is poor with regard to the recycling of secondary phosphorus, since the toilet waste, which contains the bulk of the phosphorus, is mixed with water from the kitchen, laundry, and shower. Before its arrival at the treatment plant, the household wastewater may be mixed with industrial wastewater and storm water, which will dilute the toilet wastewater further. Some respondents were concerned about the mixing of "pure" household wastewater with industrial wastewater, and they believed that it would be easier to market a product originating from household wastewater.

According to some respondents, the environmental movement is a major obstacle. When this alternative was chosen, it was often given a high weight. The argu- 
ment put forward was that the environmental movement has a negative attitude toward sludge use. Again, the survey showed that the arguments put forward by the environmental movement are to some extent supported by some of the respondents. For example, one expressed concern about the poor quality of the sewage sludge, and another pointed out that there are still several important questions that need to be answered.

Following the four highest ranked factors mentioned above were the legal system, the information flow, and finally the market conditions. Almost half of the respondents answered that the legal system was a hindrance. But when asked to rank how large the problem was, only about half ranked it as a major problem. Quite an interesting comment was the suggestion that sewage sludge is under harder regulatory pressure than commercial fertilizers. This suggests either that there is a market imperfection whereby the insiders (producers and distributors of commercial fertilizers) create the entrance barrier, or that the legislators are unaware of or ignore this situation.

Almost 50 percent of the respondents thought that the flow of information was a problem, although it was usually given a low weight. It is noteworthy that almost half of those having a sludge utilization agreement council noted that this had increased the use of sewage sludge. Possibly the sludge council helps to spread essential information and to increase understanding between the parties involved [NV 1996]. A few respondents suggested that a well-informed general public would be more likely to accept the use of sewage sludge.

To some respondents, the current market conditions for fertilizer were an obstacle if a changing pattern of phosphorus use is desired. Although several respondents pointed to the environmental movement as a major obstacle, several used the argument that the low price of commercial fertilizers has led to an overuse in Western agriculture, which accords with the environmentalists' view.

\section{Ranking of the Three Most Important Determinants for Increasing Sludge Use}

Almost one-third of the respondents claimed that a change of attitude by the food industry is most important if society wants to increase sewage sludge use. Twothirds claimed that this is important. At the same time, many of the respondents claimed that consumers' views on sewage sludge are important, which confirms the worries of the food industry. In contrast, two of the responding municipalities have made surveys of consumers' attitudes. It turns out that in the first survey, 75 percent of the consumers interviewed felt positive toward the use of sewage sludge in farming [Piteå Municipality 1997]. The other survey showed a little lower share of positive respondents, 62 percent, but it also casts doubt on the food industry's main argument [Svedala Municipality 1997]. A large consumer survey performed in 1996 and 1997 , which interviewed 4,800 people, showed that 66 percent of the popula- 
tion accepted sludge utilization in agriculture, and another 22 percent felt positive toward sludge utilization but asked for more information [Envisys 1997].

\section{Effect of Lower Relative Price of Sludge}

The question in our survey, "If the price of commercial fertilizer doubled, would the use of sewage sludge increase," was answered with a yes by more than 90 percent of the respondents, clearly indicating that there exists a point where either quality considerations will be abandoned or relative prices will start to matter.

\section{Suggestions for Policy Changes to Increase Secondary Phosphorus Use}

To change or remedy a situation where too little secondary phosphorus is used, ${ }^{10}$ most of the respondents proposed that economic stimuli be used such as taxes on commercial fertilizers or subsidies for sludge users. Another suggestion was to change the legal restrictions so that all kinds of fertilizers face the same requirements.

\section{Ranking of Alternatives to Conventional Wastewater Treatment}

The two most promising alternative technologies to conventional wastewater treatment in the future, according to the respondents, are wastewater irrigation and phosphorus fertilizer production from sewage sludge, ${ }^{11}$ respectively. Both of these can be considered only minor changes to the existing infrastructure. Urine source separation ranked as the third most important alternative. The choice of method is highly size-dependent, which was confirmed by a few respondents. This means that different wastewater treatment methods will be suitable for different types of communities (size, closeness to agricultural land, etc.).

Some respondents pointed out the importance of utilizing the nitrogen and potassium found in wastewater, which is accomplished by wastewater irrigation. Wastewater irrigation, however, will not be a truly sustainable solution until the wastewater contains only plant nutrients and whatever pollutants that can be accepted in agriculture, since only those substances that can be allowed in our production or consumption can be accepted as pollutants in the secondary phosphorus [KSLA 1998]. 


\section{Conclusions}

Currently the food industry thinks that consumers would dislike the use of sewage sludge. This hypothesis is partly supported by the municipalities in our survey but is rejected by the three consumer surveys cited.

Further, the traditions within Swedish farming and the flow of information are important. We think that the sludge councils may be a step in the right direction. Unfortunately, our survey reveals the possibility that the total costs for the farmers when using sewage sludge may equal that of commercial fertilizer. If that is correct, and adding the uncertainty of using sewage sludge, the hesitation of the farmers to use the sludge may be rational. If this uncertainty rests on misconceptions, it is important to dispel these myths.

The respondents preferred conventional technology to increase secondary phosphorus use. The choice of solutions depends, however, on the size of the dwelling served by the system. We traced an inertia in the current wastewater infrastructure. Our survey shows that those responsible for wastewater treatment within municipalities do not regard the development of alternatives within wastewater treatment as very important. If the alternatives are desirable, this inertia may prove to be a major obstacle.

Further work within this field will include interviews and surveys concerning the demand side of the secondary phosphorus market, i.e., the farmers.

\section{Notes}

1. How well the phosphorus in sewage sludge could be used by plants compared with commercial fertilizers and the content of pollutants in sewage sludge.

2. Sludge, for agricultural use, must have as low a metal content as manure from the year 2000 [NV 1996].

3. The Federation of Swedish Farmers is a mixture of an interest group and a large firm.

4. Cadmium is one great concern since it is a metal that is assimilated by plants and hence can pose a health risk to animals and humans.

5. This means that the sludge has such good quality that it can be the only phosphorus source applied to agricultural land without exceeding the strict cadmium deposit regulation.

6. Another method currently being investigated in both Norway and Sweden is to reuse fill material from subsurface flow wetlands and infiltration beds that has been subjected to wastewater and is hence charged with phosphorus [personal communication, Tore Krogstad, Norwegian University of Agriculture, and Lars Hylander, Uppsala University, Sweden].

7. Clearly, the price of sewage sludge is restricted upwards by the price of commercial fertilizer and farmyard manure.

8. Depending on whether using sewage sludge is good or bad, the price may increase or decrease, respectively. Those opposing sewage sludge in agriculture would claim that the negative external effects would raise this price considerably. Those who favor the use of sewage sludge, on the other hand, could point toward positive external effects. 
9. This suggestion concerns the possibilities of market failure and suggests that the vested interest of the Federation of Swedish Farmers may have unwanted effects.

10. This statement is seen from the supply perspective. We agree with the user (and some of the suppliers) who thinks that using sewage sludge may be an option, and limited use now may give important information on future possibilities.

11. The production of phosphorus fertilizer from sewage sludge is also an alternative brought forward by the Royal Swedish Academy of Agriculture and Forestry [KSLA 1998].

\section{References}

Brett, S., J. Guy, G. K. Morse, and J. N. Lester. Phosphorus Removal and Recovery Technologies. London: Selper Publications, 1997.

Envisys. "Consumer Reactions to Sewage Sludge-a Synthesis of 5 Opinion Polls on Sludge Utilization for Food Production" (in Swedish). Environmental Systems Inc. (1997).

Hanaeus, Ȧsa, and Erica Johansson. "Urine Source Separating Systems-Inventory, Evaluation, and Laboratory Experiments" (in Swedish). Master's Thesis no. 1996:176E, Lulea University of Technology, Sweden, 1996.

Höglund, C., T. A. Stenström, A. Sundin, H. Jönsson, and B. Vinner. "Hygienic Quality of Source Separated Urine Based on the Analysis of Faecal Indicator Bacteria." RAMIRAN 98, 8th International Conference, Rennes, Brittany, France, May 26-29, 1998.

Jenssen, Petter D., and Carl Etnier. "Ecological Engineering for Wastewater and Organic Waste Treatment in Urban Areas." In Water-saving Strategies in Urban Renewal: European Approaches. Berlin: Dietrich Reimer Verlag, 1997.

Johansson, Birgitta. "Positive Responses from Arla." VAV-nytt no. 1 (1997).

Kemira. Annual Reports. Various years.

Kirchmann, Holger. "Household Compost, Sewage Sludge, and Industrial Waste in Agriculture: Problems, Risks and Research Tasks." (In Swedish) Agricultural University of Sweden, Consultant Department Report no. 137 (1988).

. "Phosphorus Flows in Swedish Society Related to Agriculture." Kungliga Skogs- ach Lantbruksakademiens Tidskrift 135, no. 7 (1998): 145-156.

KSLA. "Recycling in the City/Countryside." (In Swedish). Kungliga Skogs- och Lantbruksakademiens Tidskrift 137, no. 18 (1998).

Larsson, Liselott. "Sludge from Wastewater Treatment Plants-a Resource in a Recycling Society." (In Swedish) Swedish Technology Attachés: Foreign Report USA no. 9506 (1995).

Levlin, Erik, Lars Westlund, and Bengt Hultman. "Removal of Heavy Metals and Toxic Organic Compounds from Sewage Sludge" (in Swedish). Swedish Water and Wastewater Works Association, Report no. 8 (1996).

Norsk Hydro. Annual Reports. Various years.

NV. "Agreement between the Farmer's Association, the Water and Wastewater Works Association, and the Swedish EPA Regarding Sludge Utilization in Agriculture" (in Swedish). Environmental Protection Agency, Sweden, Report no. 4665 (1996).

. "Phosphorus and Energy from Sewage Sludge" (in Swedish). Environmental Protection Agency, Sweden, Report no. 4822 (1997).

Pettersson, O. "Recycling in Agriculture and Society" (in Swedish). Aktuellt frän Lantbruksuniversitetet 408. Uppsala, 1992.

Piteå Municipality Consumer Survey, 1997.

SCB. "The European Environment" (in Swedish). Statistics Sweden (1995a).

. "Swedish Official Statistics" (in Swedish). Statistics Sweden (1995b).

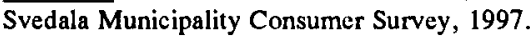


Copyright of Journal of Economic Issues is the property of Association for Evolutionary Economics and its content may not be copied or emailed to multiple sites or posted to a listserv without the copyright holder's express written permission. However, users may print, download, or email articles for individual use. 